\title{
Pulmonary rehabilitation in moderate pulmonary hypertension
}

\author{
Jhonatan Betancourt-Peña ${ }^{1,2}$, Nathalie Torres-del Castillo1, Juan Carlos Ávila-Valencia ${ }^{1,3}$, and \\ Vicente Benavides-Córdoba ${ }^{1}$ \\ 1. Faculty of Health and Rehabilitation, University National School of Sports, Cali, Colombia \\ 2. Faculty of Health, University of Valle, Cali, Colombia \\ 3. Faculty of Health, University Santiago de Cali, Cali, Colombia
}

\section{CASE STUDY}

Please cite this paper as: Betancourt-Peña J, Torres-del Castillo N, Ávila-Valencia JC, Benavides-Córdoba V. Pulmonary rehabilitation in moderate pulmonary hypertension. AMJ 2018;11(7):384-389. https://doi.org/10.21767/AMJ.2018.3467

\section{Corresponding Author:}

\section{Jhonatan Betancourt-Peña}

Faculty of Health and Rehabilitation, University National School of Sports, Cali, Colombia

Email: johnnatanbp@hotmail.com

\section{ABSTRACT}

\section{Introduction}

Pulmonary Rehabilitation has been used in Chronic Obstructive Pulmonary Disease, becoming an essential strategy in its treatment; however, in pathologies such as Pulmonary Hypertension, the benefits in the quality of life and tolerance to the effort are still discussed. Therefore, the aim of this case report is to evaluate the effect of an integral pulmonary rehabilitation intervention in a patient with moderate pulmonary hypertension secondary to respiratory disease.

\section{Case details}

A patient with moderate pulmonary hypertension secondary to lung disease, who attended an integral pulmonary rehabilitation program during 8 weeks of muscle training, aerobic exercise, breathing exercises, individualized education and psychological/ nutritional counselling were performed.

\section{Results}

Significant improvement in tolerance to effort, reduction of symptoms and health-related quality of life after the intervention was achieved.

\section{Conclusion}

Pulmonary rehabilitation in moderate pulmonary hypertension generated beneficial changes in terms of symptoms and functionality in the patient reported.

\section{Key Words}

Rehabilitation, pulmonary hypertension, quality of life

\section{Implications for Practice:}

\section{What is known about this subject?}

Although pulmonary rehabilitation is useful in patients with chronic respiratory diseases, the evidence of PR in $\mathrm{PH}$ is still inconclusive.

\section{What new information is offered in this case study?}

A pulmonary rehabilitation program enhances the benefits in functional capacity and dyspnoea in a patient with moderate Pulmonary Hypertension and Tuberculosis sequelae.

3. What are the implications for research, policy, or practice?

The importance of the approach in PR in some cases of $\mathrm{PH}$ could offer beneficial results for patients.

\section{Background}

Pulmonary hypertension (PH) groups a number of pathologies of different aetiology, characterized by an increase in the mean pulmonary artery pressure (mPAP) with values greater than $25 \mathrm{mmHg}$ at rest or $>30 \mathrm{mmHg}$ at exercise. ${ }^{1}$ It is classified as mild (mPAP $35-40 \mathrm{mmHg}$ ), moderate (mPAP 40-60 mmHg) and severe (mPAP $>60 \mathrm{mmHg})^{2}$

$\mathrm{PH}$ is pathology with an average survival time of 3 to 5 years, and its condition can vary by geographical, socioeconomic and pathological conditions. In countries such as Argentina, the estimated prevalence is 15 cases per 
1 million inhabitants and the incidence is of 2.4 per 1 million inhabitants per year. ${ }^{3}$ It is estimated that in Spain the incidence was 3.3 cases/million/year and the prevalence was 15.3 cases/million/year in 2008, according to the REHAP registry. ${ }^{4}$ In Colombia, epidemiological data on pulmonary hypertension in adults are not known with precision; ${ }^{5}$ considering its variability and impact on public health, it is recommended that developing countries have their own registry.

Group 3 of the disease is one of the most common and ends up generating cor pulmonale in its terminal stage. The diseases included in this group are chronic obstructive pulmonary disease (COPD), interstitial disease and obstructive sleep apnoea. ${ }^{6}$

There are reports of patients with sequelae of pulmonary tuberculosis who, after several years of healing, ended up acquiring $\mathrm{PH}$, and that conclude that the early treatment of this condition is essential to prevent complications. ${ }^{7}$ Reports like that of Verma, suggest that although there is no clear association between $\mathrm{PH}$ and pulmonary tuberculosis (TB), there are studies in the Middle East that establish the possible causes for the development of $\mathrm{PH}$ in patients with TB. $^{8}$

Symptoms originate late in most cases, and patients typically present dyspnoea on exertion, fatigue, angina, and edema, ${ }^{9}$ generating limited functionality, intolerance to exercise, and compromise of their health-related quality of life (HRQOL).

The primary goals of treatment are to reduce symptoms, stabilize the functional class and prevent the progression of the disease. ${ }^{10}$ Pulmonary rehabilitation (PR) as a complementary therapy is very beneficial in functional capacity, tolerance to exercise and HRQoL, however, it has not been possible to obtain results similar to those of diseases such as COPD where it has proven evidence. ${ }^{11}$ Therefore, it is necessary to report how standardized PR can act on symptoms and quality of life of patients with moderate pulmonary hypertension secondary to chronic lung disease.

\section{Case Details}

The patient was a male of 51 years old, married, from the city of Cali - Colombia, belonging to a low socio-economic stratum, referred by pulmonology under diagnosis of moderate pulmonary hypertension secondary to chronic lung disease. The patient presented pulmonary TB diagnosed years ago and treated satisfactorily with a tetraconjugate scheme based on Isoniazide, Rifampicin, Pyrazinamide and Ethambutol. In addition to the above, the patient had: arterial hypertension, dyslipidaemia, congestive heart failure (CHF) and bronchiectasis.

No visits to the emergency room or hospitalizations were reported in the last year due to respiratory causes and the patient was non-smoker and had not been exposed to wood smoke. He was classified in stage III of the WHO functional classification and used supplemental oxygen at home. ${ }^{6}$

The diagnosis of $\mathrm{PH}$ was made by right heart catheterization in which it was obtained: mPAP: $42 \mathrm{mmHg}$, pulmonary wedge pressure: $16 \mathrm{mmHg}$, cardiac output 4.82 litres/min, pulmonary vascular resistance: 8.2 Wood units. The transthoracic echocardiogram reported: ejection fraction of the left ventricle 62 per cent, mitral valve with mild insufficiency, diastolic function of the left ventricle: alteration of relaxation with increase in filling pressures, left ventricle with concentric hypertrophy, left atrium of normal dimensions, lower vena cava dilated with adequate inspiratory collapse, right cavities of normal dimensions, structurally normal pulmonary valve.

Other paraclinical exams yielded the results: Prothrombin time: 17.3 seconds, INR 1.72, Haemoglobin: $14.3 \mathrm{~g} / \mathrm{dL}$, Haematocrit: 46.4 per cent, corpuscular mean volume: 75.7fL, Platelets: $287,000 \mathrm{~mm}^{3}$, leukocytes: $3140 \mathrm{ml} / \mathrm{mm}^{3}$, acid uric: $8.54 \mathrm{mg} / \mathrm{dL}$, HDL cholesterol $32.6 \mathrm{mg} / \mathrm{dL}$, total cholesterol: $128 \mathrm{mg} / \mathrm{dL}$, creatinine: $1.35 \mathrm{~g} / 24 \mathrm{~h}$, glycemia: $83.8 \mathrm{mg} / \mathrm{dL}$, blood urea nitrogen: $18.2 \mathrm{mg} / \mathrm{dL}$, potassium: $4.27 \mathrm{mEQ} / \mathrm{L}$, sodium: $141.1 \mathrm{mEQ} / \mathrm{L}$ and triglycerides: $153.2 \mathrm{mg} / \mathrm{dL}$.

As a sequel to pulmonary TB, the patient presented a moderate restrictive pattern with Forced Vital Capacity of 60 per cent, Forced Expiratory Volume 69 per cent and FEV1/FVC ratio of 115 per cent of the predicted value in spirometry.

The pharmacological treatment for the management of $\mathrm{PH}$ consisted of: Phosphodiesterase 5 inhibitors; for comorbidities, beta2-adrenergic agents, corticosteroids and inhaled anticholinergics were formulated; furthermore, the patient received lipid-lowering agents and angiotensin I receptor antagonists.

Sociodemographic and clinical information of the patient was taken; assessments were made by a physiotherapist at the beginning and end of the PR program, such as the 6 minute walk test (6MWT), VO2 estimated was obtained 
with the equation developed by the American College of Sports Medicine: speed $\times 0.1+3.5^{12}$ body mass index (BMI), WHO functional classification ${ }^{6}$ and quality of life related to health with the Self-administered Chronic Respiratory Disease Questionnaire (CRQ-SAS), which includes 20 questions in 4 domains: dyspnoea, fatigue, emotional and control; in which for each one of the domains a series of questions is assigned that reflect their perception of health in the last 4 weeks. The scores in the domains vary between zero (equivalent to the worst performance) and a maximum of seven (being the best performance). At the end of PR, a clinically significant improvement is considered when some or all of the average domains increase 0.5 points. ${ }^{13-15}$

\section{Physical examination}

1.67 meters high, weight of $69 \mathrm{~kg}$, BMI of $24.74 \mathrm{~kg} / \mathrm{m}^{2}$ with normal rating. Vital signs showed blood pressure of $100 / 60 \mathrm{mmHg}$, heart rate of 81 beats per minute, respiratory rate of 18 breaths per minute, oxygen saturation (SpO2): 90 per cent with inspired fraction of oxygen (FiO2) of 32 per cent.

\section{Limitation in functionality and quality of life}

Patient who does not present dyspnoea at rest, but does present it when performing activities such as climbing steps or performing marches of more than 100 meters. The patient reports limitations in his work and conjugal life, as well restrictions in the participation of social activities.

\section{Intervention}

The physiotherapeutic intervention was carried out in the PR program, which included 24 sessions in 3 sessions per week for 8 weeks. The sessions included: 5-minute warm-up with self-loading activities and positions (bipedal-seated), strength training for 20 minutes, muscular strengthening of upper and lower limbs in 4 sets of 12 repetitions with 1 minute of rest at 40 per cent of the maximum resistance (MR), which was increased to 60 per cent of the MR at the fourth week. ${ }^{16}$ Subsequently, the patients performed RMSG exercises for 10 minutes. ${ }^{17,18}$

In the central activity patients performed continuous exercise in endless band and Recumbent bicycle for 30 minutes, initiating at 60 per cent of the maximum heart rate, ${ }^{19}$ which was increased to tolerance of the patient in the modified Borg scale, to maintain a score of between 3 (moderate) and 5 (severe), ${ }^{20}$ and administering supplemental oxygen to patients who had a desaturation $\geq$ 4 or who during exercise had a partial oxygen saturation (SpO2) of less than 90 per cent. At the end of the session, patients performed breathing and mobility techniques of the thorax; the education activities were carried out by professionals in physiotherapy, developed with individual and group sessions on topics that included: knowledge of the disease, use of medications, recommendations for the use of oxygen, diet, measures against anxiety, relaxation techniques and breathing exercises at home, in addition to receiving psychotherapy and nutrition counselling. ${ }^{21}$

\section{Results and Discussion}

Table 1 shows the results regarding the symptoms and the functional classification of the patient. There were significant differences represented in the WHO and mMRC functional classification scores as well as the ejection fraction of the left ventricle. The dyspnoea of the activities of daily life on the mMRC scale had a 50 per cent decrease in their score, from 4 to 2 , where at the beginning of the rehabilitation dyspnoea prevented the patient from leaving the house or doing activities such as dressing or undress, to have dyspnoea that allows him to wander at a slow pace, since the patient still cannot keep pace with other people of his same age on flat ground. These functional changes allowed the patient to achieve more independence, especially in activities within his home, making necessary the help of family members only for activities that required going out.

Regarding tolerance to exertion, after 8 weeks of PR, the patient presented significant clinical improvement. In the TC6M went from an initial distance of 312 meters to finish with 420 meters after 6 minutes, being a difference of 108 meters after the PR. Likewise, supplementary oxygen requirements changed thanks to the implemented protocol, decreasing by 4 per cent the FIO2 needed to complete the test. All the above is reflected in the HRQoL, that showed a superior improvement in the control domain of the disease, a situation that allowed a decrease in the total score of the questionnaire, going from 5.8 to 6.1 points (it is necessary to clarify that the difference of the CRQ before and after PR is not clinically significant). Additionally, the patient stated that his marital relationships improved substantially.

The PR intervention allowed improvement in several aspects in the patient: increased tolerance to effort reduced symptoms and improved functional classification. There is evidence that shows that exercise generates beneficial effects for patients with $\mathrm{PH}^{22}$ muscle training, breathing exercises and admission to the RP program when the disease was in a moderate stage, allowed to overcome what has been achieved by several previously conducted studies. Regarding the 6MWT, this allows to assess the functional 
status and response to treatment of patients with various cardiopulmonary diseases. $^{23}$

The distance is considered one of the basic pillars in mortality factors and improvement over treatments, because it is related to the ejection fraction of the heart and the response to exercise. In this study, the patient showed improvement in the distance with a difference of 108 meters. This difference is much higher compared to other studies presented in the literature, like that of Mereles in $2006,{ }^{24}$ in which they found an average difference of 85 meters, or that of Grunig and Cols, ${ }^{25}$ who after a 3-week PR training showed positive changes of 59 meters. This means that with longer periods of training and with different intervention strategies, better results are achieved in the $6 \mathrm{MWT} 24$, because they generate better adaptation to exercise with hemodynamic and vascular changes that last longer. $^{26}$ Finally, Chan's study showed an average improvement of 56 meters compared to the initial measurement. ${ }^{27}$

Some previous studies have suggested that $P R$ improves the ability of the muscle to increase its VO2 during exercise; ${ }^{28}$ Chronic respiratory diseases can limit patients more for muscle fatigue than for ventilatory disorders such as TB, ${ }^{29}$ although no muscle strength data were collected in the present study, it could be hypothesized that physiological changes occurred at the muscular level that make the person walk more meters; go according to an increase in muscle strength.

The results presented by the patient reported in the present investigation are superior to those previously compared. This situation can be due to several intrinsic or extrinsic factors that can generate changes. One of these factors may be that the patient was in a moderate stage of the disease, and if we compare this information with the previously exposed studies, it may be an important measure, since, although in the other investigations there were also patients with moderate $\mathrm{PH}$, a good part of these had participants with high levels of mPAP that classified them as severe in the classification of the disease. Another important factor is the duration of training, which lasted 8 weeks compared to the Grunig protocol that lasted three. ${ }^{25}$

Drowning is one of the most persistent symptoms in patients. The patient in this study had a 50 per cent reduction in his dyspnoea, going from 4 to 2 , a situation that completely changes the outlook regarding the appearance of symptoms during the performance of activities of daily living. There were benefits in the functional classification of the WHO, starting in class III and ending in class II, which is similar to that found by Ehlken et al., ${ }^{30}$ who in a clinical trial found in 3 weeks of training significant improvements in the functional class of $2.8 \pm 0.6$ to $2.4 \pm 0.5$; however, although in this and in Grunig's study ${ }^{31}$ there was a decrease in the average classification score, it could not be established if they changed the grade from one stage to another, as it does in the case reported by us.

Moreover, the desaturation during the exercise is progressive by increasing the effort. This situation was evidenced when the desaturation increased at the end of the $6 \mathrm{MWT}$, since to walk a greater distance the patient made a greater physical effort causing fatigue and a higher score on the borg scale, ${ }^{25}$ it is also known that the a history of TB maybe worsen this situation in the test. ${ }^{21}$ so it was controlled during exercise sessions by supplying supplemental oxygen. ${ }^{25}$

It has been reported that patients with $\mathrm{PH}$ have debilitating symptoms that negatively impact HRQoL, which mainly generates a progressive deterioration in physical capacity and psychological status. ${ }^{32}$ These statements are very similar to those found in our study because the patient presented greater problems in the fatigue and dyspnea domain of the CRQ-SAS questionnaire, clearly evidencing the commitment in the respiratory physical capacity. In turn, as mentioned by some authors, the interventions based on aerobic exercise, muscle strengthening of upper and lower limbs and respiratory muscle exercises, have clear benefits in the quality of life of patients with pathology of pulmonary origin, ${ }^{33}$ which benefits for patients, not only in the domains related to the symptomatology, but also in the emotional domains and the control of the disease (Table 2).

It should be clarified that although there were positive changes in this variable, these did not reach the significant minimum difference of 0.5 in the total score.

One of the most important aspects of the study is the sequel of pulmonary tuberculosis of the patient, reflected in the moderate pulmonary restriction evidenced by the variable FVC of spirometry. Although pulmonary TB is not considered as a transcendental factor in the appearance of $\mathrm{PH}$, physiopathologically there is evidence that there is some association. ${ }^{8}$ In the future, it is necessary to expand the information on these two pathologies when they act together, through cases and controls epidemiological studies that allow establishing the association. 


\section{Conclusion}

Patients with $\mathrm{PH}$ suffer from marked limitations in functional capacity, deterioration of quality of life and symptoms. In the case presented, the RP generated benefits on these limitations, through the combination of aerobic exercise and the integral intervention of several health professionals, reflected in improvement of tolerance to effort, symptomatology and quality of life related to health.

\section{References}

1. Simonneau G, Galiè N, Rubin $U$, et al. Clinical classification of pulmonary hypertension. J Am Coll Cardiol. 2004;43(12):S5-S12.

2. Galiè N, Humbert M, Vachiery JL, et al. 2015 ESC/ERS Guidelines for the diagnosis and treatment of pulmonary hypertension: the Joint Task Force for the Diagnosis and Treatment of Pulmonary Hypertension of the European Society of Cardiology (ESC) and the European Respiratory Society (ERS): endorsed by: Association for European Paediatric and Congenital Cardiology (AEPC), International Society for Heart and Lung Transplantation (ISHLT). Eur Respir J. 2015;46:903-75.

3. Federación Argentina de Cardiología. Design of the HINPULSAR Registry (HIpertensióN PULmonar y aSociaciones en la ARgentina) Pulmonary hypertension and associations in Argentina. Insuf Card. 2010;5(3):126131.

4. Jiménez $C$, Escribano $P$, Barberà J, et al. Epidemiology of $\mathrm{PAH}$ in Spain: preliminary analysis of the Spanish Pulmonary Hypertension Registry (REHAP). Rev Esp Cardiol. 2009;62(Suppl 3):58.

5. Villaquiran-Torres C. Pulmonary arterial hypertension in Bogotá: description of a group of patients belonging to the Institutional Program of the Colombian Pneumological Foundation. Rev Colomb Neumol. 2010;22(1):3-10.

6. Simonneau G, Robbins IM, Beghetti M, et al. Updated clinical classification of pulmonary hypertension. Journal of the American College of Cardiology. 2009;54(1):S43S54.

7. Ahmed AEH, Ibrahim AS, Elshafie SM. Pulmonary hypertension in patients with treated pulmonary tuberculosis: analysis of 14 consecutive cases. Clin Med Insights Circ Respir Pulm Med. 2011;5:1-5.

8. Verma AK. Tuberculosis and pulmonary hypertension: Commentary. Lung India. 2016;33(2):232-233.

9. McLaughlin VV, Gaine SP, Howard LS, et al. Treatment goals of pulmonary hypertension. J Am Coll Cardiol. 2013;62(25 Supplement):D73-D81.

10. Poch DS. Case report: a patient with pulmonary arterial hypertension transitioning from a PDE-5 inhibitor to
Riociguat. BMC Pulm Med. 2016;16(1):82.

11. Yawn BB, Thomashaw B, Mannino DM, et al. The 2017 update to the COPD foundation COPD pocket consultant guide. Chronic Obstr Pulm Dis. 2017;4(3):177-185.

12. American College of Sports Medicine. ACSM's guidelines for exercise testing and prescription. Ninth Edition. Lippincott, Williams \& Wilkins; 2014.

13. Betancourt-Peña J, Muñoz-Erazo BE, Mora-Guerra RV. Quality of life in patients with chronic obstructive pulmonary disease income of pulmonary rehabilitation program. Rev Col Reh. 2015;14(1):46-53.

14. Guyatt GH, Berman LB, Townsend M, et al. A measure of quality of life for clinical trials in chronic lung disease. Thorax. 1987;42(10):773-778.

15. Vigil L, Güell MR, Morante $F$, et al. The validity and sensitivity to change of the Spanish self-administered version of the Chronic Respiratory Questionnaire (CRQSAS). Archivos de Bronconeumología (English Edition). 2011;47(7):343-349.

16. Betancourt-Peña J, Hurtado-Gutiérrez H. Effects of pulmonary rehabilitation in patients with diffuse interstitial lung disease. Fisioterapia. 2015;37(6):286292.

17. Ito $M$, Kakizaki F, Tsuzura $Y$, et al. Immediate effect of respiratory muscle stretch gymnastics and diaphragmatic breathing on respiratory pattern. Int Med. 1999;38(2):126-132.

18. Minoguchi $H$, Shibuya $M$, Miyagawa $T$, et al. Cross-over comparison between respiratory muscle stretch gymnastics and inspiratory muscle training. Internal medicine. 2002;41(10):805-812.

19. Newman JH, Robbins IM. Exercise training in pulmonary hypertension implications for the evaluation of drug trials. Circulation. 2006;114(14):1448-1449.

20. Egan C, Deering BM, Blake C, et al. Short term and long term effects of pulmonary rehabilitation on physical activity in COPD. Respiratory medicine. 2012;106(12):1671-1679.

21. Betancourt-Peña J, Muñoz-Erazo BE, Hurtado-Gutiérrez $H$. Effect of pulmonary rehabilitation in quality of life and functional capacity in patients with tuberculosis sequela. Nova. 2015;13(24):47-54.

22. Weissmann N, Peters DM, Klöpping C, et al. Structural and functional prevention of hypoxia-induced pulmonary hypertension by individualized exercise training in mice. Am J Physiol Lung Cell Mol Physiol. 2014;306(11):L986-L995.

23. Ciro-Casanova M, Velasco-Gonzales MdV, De TorresTajes JP. The 6 minute walk test in respiratory diseases. Medicina respiratoria. 2011;4(1):57-67.

24. Mereles D, Ehlken N, Kreuscher $S$, et al. Exercise and 
respiratory training improve exercise capacity and quality of life in patients with severe chronic pulmonary hypertension. Circulation. 2006;114(14):1482-1489.

25. Grünig E, Lichtblau M, Ehlken N, et al. Safety and efficacy of exercise training in various forms of pulmonary hypertension. Eur Respir J. 2012;40(1):84-92.

26. Chia KS, Faux SG, Wong PK, et al. Randomised controlled trial examining the effect of an outpatient exercise training programme on haemodynamics and cardiac MR parameters of right ventricular function in patients with pulmonary arterial hypertension: the ExPAH study protocol. BMJ. 2017;7(2):e014037.

27. Chan L, Chin LM, Kennedy M, et al. Benefits of intensive treadmill exercise training on cardiorespiratory function and quality of life in patients with pulmonary hypertension. Chest. 2013;143(2):333-43.

28. Koch B, Schäper C, Ittermann T, et al. Reference values for cardiopulmonary exercise testing in healthy volunteers - the SHIP Study. Eur Respir J. 2009;33(2):389-97.

29. Saey D, Debigare R, LeBlanc $P$, et al. Contractile leg fatigue after cycle exercise - a factor limiting exercise in patients with chronic obstructive pulmonary disease. Am J Respir Crit Care Med. 2003;168(4):425-430.

30. Ehlken $\mathrm{N}$, Lichtblau $\mathrm{M}$, Klose $\mathrm{H}$, et al. Exercise training improves peak oxygen consumption and haemodynamics in patients with severe pulmonary arterial hypertension and inoperable chronic thromboembolic pulmonary hypertension: a prospective, randomized, controlled trial. Eur Heart J. 2015;37(1):3544.

31. Grünig E, Ehlken N, Ghofrani A, et al. Effect of exercise and respiratory training on clinical progression and survival in patients with severe chronic pulmonary hypertension. Respiration. 2011;81(5):394-401.

32. Mathai SC, Ghofrani HA, Mayer E, et al. Quality of life in patients with chronic thromboembolic pulmonary hypertension. Eur Respir J. 2016;48:526-537.

33. Csikesz N, Lee MM, Krishnan I, et al. Pulmonary rehabilitation for patients with pulmonary hypertension: A single center experience. Am J Respir Crit Care Med. 2016. A2317.

\section{ACKNOWLEDGEMENTS}

The authors thank the patient for allowing this study.

\section{PEER REVIEW}

Not commissioned. Externally peer reviewed.

\section{CONFLICTS OF INTEREST}

The authors declare that they have no competing interests.

\section{PATIENT CONSENT}

The authors, Betancourt-Peña Jhonatan, Torres-del Castillo Nathalie, Ávila-Valencia Juan Carlos, Benavides-Córdoba Vicente, declare that:

1. They have obtained written, informed consent for the publication of the details relating to the patient(s) in this report.

2. All possible steps have been taken to safeguard the identity of the patient(s).

3. This submission is compliant with the requirements of local research ethics committees.

Table 1: Clinical and aerobic capacity changes after PR

\begin{tabular}{|l|l|l|}
\hline \multirow{2}{*}{} & \multicolumn{2}{l|}{ PR } \\
\cline { 2 - 3 } & Before & After \\
\hline Distance (mts) & 312 & 420 \\
\hline Basal Dyspnoea & 0 & 0 \\
\hline Dyspnoea after 6MWT & 0 & 3 \\
\hline mMRC Dyspnoea & 4 & 2 \\
\hline \% Desaturation & 10 & 16 \\
\hline SaO2 Basal & 90 & 92 \\
\hline SaO2 After 6MWT & 80 & 76 \\
\hline FiO2 \% & 32 & 28 \\
\hline Vo2e ml/kg/min & 87 & 10.5 \\
\hline WHO functional classification & III & II \\
\hline LVEF & $62 \%$ & $66 \%$ \\
\hline
\end{tabular}

Mts: Meters, 6MWT: Six minutes walking test, mMRC: Modified Medical Research Council FiO2: Fraction of inspired Oxygen, VO2e: Estimated oxygen consumption LVEF, Left Ventricle Ejection Fraction

Table 2: Quality life changes after

\begin{tabular}{|l|l|l|}
\hline \multirow{2}{*}{ Domain CRQ } & PR & \\
\cline { 2 - 3 } & Before & After \\
\hline Dyspnoea & 4.6 & 4.6 \\
\hline Fatigue & 6.5 & 6.7 \\
\hline Emotional & 6.4 & 6.4 \\
\hline $\begin{array}{l}\text { Disease } \\
\text { Control }\end{array}$ & 6 & 7 \\
\hline Total CRQ & 5.8 & 6.1 \\
\hline
\end{tabular}

CRQ: Chronic Respiratory Questionnaire 